\title{
The Execution Strategy of Reforming Indian Ordnance Factories (OFB) Through Corporatisation
}

\author{
Jyoti Prakash Dash ${ }^{1,}$, Anuraag Dash ${ }^{2, *}$ \\ ${ }^{1}$ India Government Mint, Hyderabad, India \\ ${ }^{2}$ National Institute of Technology, Tiruchirappalli, India \\ Email address: \\ jpdash@spmcil.com (J. P. Dash), 114119012@nitt.edu (A. Dash) \\ ${ }^{*}$ Corresponding author
}

\section{To cite this article:}

Jyoti Prakash Dash, Anuraag Dash. The Execution Strategy of Reforming Indian Ordnance Factories (OFB) Through Corporatisation. European Business \& Management. Vol. 6, No. 6, 2020, pp. 143-150. doi: 10.11648/j.ebm.20200606.13

Received: November 16, 2020; Accepted: November 27, 2020; Published: December 8, 2020

\begin{abstract}
The Ministry of Defence (MOD) would like to see Indian Ordnance Factories, also known as Ordnance Factory Board (OFB) grow to the next level of turnover, exports and self-reliance through Corporatisation, a reform that holds the promise of catapulting OFB into the top League of Defence Manufacturers. The Government has formed an Empowered Group of Ministers (EGoM) under the Chairmanship of Raksha Mantri (Defence Minister) to oversee and guide the entire process. This paper examines various aspects of the transformation process and widens the agenda of the debate for successful change management. This paper examines the difference between the Goals, Tools and Values to bring clarity for Strategic Transformation. The paper raises hope that although the statistics of history and research is stacked against Organisational Transformation, it is well possible to drive Transformation and make the turnaround of the organisation with an open-ended exercise, an honest intention centred on the alignment of interest amongst the stakeholders. The paper argues that transformation strategy can work better with focus on the following levers; Strategic Transformation, EcoSystem Transformation, Learning from Past and Best of Class from Industry, Unit and Corporate Level Transformation, Structural Changes from Financial Perspective, Empowerment Mechanism, Talent Management and Employee Concerns and Better Change Management through monitoring of the Consultant.
\end{abstract}

Keywords: Defence, India, OFB, Corporatisation, Change, Transformation

\section{Introduction}

The Indian national ambition to play a larger role in the new global order can be fulfilled through a strong military-industrial base and sustainable growing economy. The Government of India would like the Defence Sector turnover to reach INR 1, 75,000 Crores (US\$ 25Bn) including export of INR 35,000 Crore (US\$ 5 Billion) in Aerospace and Defence goods and services by 2025 [1]. The Government of India is keen to develop a dynamic, robust and competitive Defence industry. With the Public Sector contribution to the extent of $80 \%$ currently, this target can be achieved with twin strategy of Transformation of OFB and DPSUs (Defence Public Sector Units) for a higher level of output and allowing the Innovation and Capability of the private sector. While Transformation is a painful process, successfully manoeuvred, it can herald the beginning of a new chapter in India's Defence Capability. The Corporatisation of OFB needs detailed examination with MOD's (Ministry of Defence) appointment of a Consultant to navigate the process and formation of Empowered Group of Ministers (EGoM) under the Chairmanship of Raksha Mantri (Defence Minister) to steer the process of change [2].

\section{Background of Corporatisation}

Indian Ordnance Factories functions under the administrative control of the Department of Defence Production, Ministry of Defence. During the last decade, Ordnance Factories, known as OFB, have emerged as a significant source to meet the requirements of arms and ammunition of the Central Para Military Forces and state police forces. In the process, they are making a substantial 
contribution towards strengthening the internal security apparatus within the country. OFB works under the departmental Structure, under Ministry of Defence. OFB products are priced on a cost-based methodology without charging any profit over the cost of production for supply to the armed forces. OFB is nominated as a production agency for most of its traditional product line and competes for any new Capital Equipment through Defence Procurement Procedure. There have been complaints on the slippage of supply and quality of the products. The Government is of the opinion that the Corporatization of OFB will improve its autonomy, accountability and efficiency in Ordnance Supplies [3].

With the goal to help OFB grow to the next level of turnover, exports and self-reliance, the Government has decided to convert Ordnance Factory Board, an attached office of the Ministry of Defence, into one or more than one $100 \%$ Government owned corporate entity (ies]. Various Expert Committees set up in the past, such as TK Nair Committee (2000), Kelkar Committee (2005), Raman Puri Committee (2015) and Shekatkar Committee (2016), have already given similar recommendations to corporatise OFB [3]. It has been stated that the conversion of Ordnance Factories under the OFB into one or more $100 \%$ Government-owned public sector unit will provide functional and financial autonomy and managerial flexibility so as to enable the organisation to grow at a faster pace and play a greater role in defence preparedness of the country.

Government of India has invited an EOI-cum-RFP from India-based consulting agencies on 06-07-2020 to assist the Ministry of Defence in the process of Corporatisation of the Ordnance Factories [1]. The EOI has many lauded objectives to transform OFB such as Improvement in the quality of its products, better utilisation of capacities and assets of the OFB, optimum utilisation of Human Resources, Timely supply to the Armed forces, Higher Exports, Increased turnover/profitability etc.

A Consultant has been appointed by the Ministry to suggest Organisational structural changes and a business continuity plan for the new entities to continue on a sustainable basis. MOD has also selected M/s KPMG Advisory Services Pvt. Ltd. (Lead Consortium Member) with M/s Khaitan \& Co. Ltd. as another Consortium Member, as the Consultancy Agency for providing strategic and implementation management consulting services to assist the MOD in the process of Corporatisation of the OFB [2].

The Government is committed towards the welfare of the OF employees through dialogue at both Official and Political level. While there has been continuous dialogue through High-Level Official Committee under Additional Secretary (DP), an Empowered Group of Ministers (EGoM) under the Chairmanship of Raksha Mantri has been constituted to oversee and guide the entire process including transition support and re-deployment plan of employees while safeguarding their wages and retirement benefits [3].

Expectations are high for unleashing the power of Innovation, boosting exports exponentially, improving the quality radically, creating profitable and self-sustaining arms production system in the country, agility in absorbing Transfer of Technology (ToT), besides forming Joint Venture (JVs) with other countries including the acquisition of foreign companies.

\section{Research Methodology}

The research methodology comprised for searching for all Defence Policy Reforms undertaken by the Government of India in the context of OFB and search of publications in the Elsevier (Science Direct), Emerald, ProQuest, Google Scholar, and Taylor and Francis databases by using the keywords. However, there are hardly any papers published in the context of OFB Policy Reforms in 2020.

From the two types of Public Policy Papers, this paper focusses on Analysis, leaving aside the Policy Study. This Policy analysis is targeted for looking at implementation strategies, following the methodology and prescription $[4,5]$ and has an objective to influence policy outcomes without analysing the context and the skills of policymaking. This paper uses the criteria of like good timing and attention to the details; by recognising the limits of the possible and using those limitations creatively for persuading the policymakers to try alternate options [6]. The various criteria of Effectiveness, Feasibility and Improvability are considered leaving out the equity dimension, not considered important for Self-Reliance of the Nation, for judging alternate policy options for long term impact [7].

\section{Terms of Reference (ToR) of the EGoM}

The Terms of Reference (ToR) of the EGoM inter alia include [3].

Quote

(1) Decision on the conversion of OFB into a single Defence Public Sector Undertaking (DPSU) or as multiple DPSUs;

(2) Matters related to various categories of employees including protection of their salary and pension of existing employees;

(3) Financial support that may be provided to the entity/entities to make them economically viable and self-reliant;

(4) Grandfathering of orders already being executed by OFB or for which facilities created in OFB;

(5) Treatment for land assets of OFB

The composition of EGoM along with ToRs have been communicated to the OFB, and various Federations, Unions and Associations at Board/ Factory/Unit level and they have been requested to place all their suggestions, issues and concerns relating to Corporatization of OFB before the EGoM.

Unquote

There is a need to articulate the issues and concerns and elicit public debate so that the best strategy is chosen for reforms. 


\section{Negotiating the Transformation Process}

Anecdotes are not statistically significant, but their emotional appeal conveys a better message. Hence, a compelling anecdote is presented for better appreciation. Two men seated together in a building are at odds on whether to keep a window open or closed. Hearing this feud, a third person asks about the dispute. One gentleman demands to close the window to avoid a draft. The second gentleman wants the window open for the fresh air. The third person then goes into the next room and opens a window. This simple solution resolves the problem by providing the fresh air one of the men wanted while negating the issue of the draft for the other. This creative solution happily satisfies both sides' interests. The solution to any complex problem can be found through open box thinking. Corporatisation, a change over from existing set up, poses challenges of a different dimension and needs to be addressed creatively.

There has been stiff resistance from the employees against the Corporatization. The talks, held under the chairmanship of Additional Secretary, Defence Production has not been to cut the ice, although made in a harmonious environment. In negotiations, often the discussion has led to a stalemate when both parties stick to their positions, but not finding common ground to the interests. It is imperative that both sides should agree on the key issues at stake before even attempting to resolve the issues. Otherwise, both the sides will be at cross purposes, and resolution will be extremely difficult-if not impossible. The commonality in the purpose can make the negotiation moving in a positive direction.

For a better explanation, let us create two scenarios; One in which Corporatisation happens smoothly with the changeover and ensuring better compensation of employees, but it fails to bring dynamism, faster decision making, higher turnover, and increased export. The second situation is in where both parties agree to a different alternative model of autonomy and Corporation, and the new entity becomes a force to reckon with higher output and productivity and innovative products for the Indian Armed Forces. The obvious option would be a preference for the second option. Long term impact must prevail over any short quick wins.

Autonomy, accountability and efficiency are the values worth aspiring for, but they are not the end in themselves. What happens, if all of them are ensured, but the performance is not enhanced in terms of higher turnover and exports, the higher customer value proposition in terms of delivery of contemporary quality equipment? Thus, the values will be more meaningful with the results. Values, although extremely important, cannot be the sole justification for reforms in a business context, unless the same cannot lead to higher performance.

It should be noted that Corporatisation is a tool and need not be seen as a Goal. It is considered to be a mechanism for the Transformation of OFB. When the organisation is pushed to a zone for self-survival, Innovation normally happens to fight the competition. However, mere structural change is a poor substitute for Strategy and Process Engineering. If we see the literature of business organisation, the form, otherwise known as Structure keeps on changing from time to time so that the organisation stay relevant. What makes the oil of the engine of the organisation moving is a basket of core competency, which is converted to marketable products, ensuring profit for the organisation due to superior strategy, process and execution ability of the leadership. The Structure is the internal response of the organisation for strategic alignment to the market.

In light of the above discussions, the Terms of Reference needs to broad enough to drive Transformation, not implement a priori solution. The unintended consequences need to be discussed and debated for any chosen means of Transformation. The terms of reference should enable critical examination of the assumption made and estimating risks associated with the same so that that risk can be contained and mitigated.

The Consultant and EGoM have got a great responsibility in ensuring that executing this 'reform' will indeed make the ordnance factories more efficient and serve the cause of self-reliance better. Although the statistics of history and research is stacked against the success of Transformation, it is well possible to drive Transformation and make the turnaround of the organisation with open-ended exercise, an honest intention centred on the alignment of interest, not a fight over positions.

Michael Hammer and James Champy in their book titled "Reengineering the Corporation", the book stated there is $70 \%$ failure rate for the organisations that undertake a reengineering effort do not achieve the dramatic results they intended [8]. A Forbes Article quotes research from McKinsey and Company and states that $70 \%$ of all transformations fail [9]. According to 2008 research from IBM, the need to lead change is growing, but our ability to do it is shrinking [10]. Hence people often get discouraged and eventually give up during the painful change process. Boston Consulting Group says as many as $50 \%$ of organisational change projects don't achieve their objectives, and with large-scale transformation programs, the failure rate jumps to $75 \%$ [11]. Thus, it is imperative that change management initiative is taken with due care, as the nation cannot afford to fail from this grand experiment.

\section{Crafting the Terrain of Change}

The good news is that MOD has kept flexibility in designing of the Consultancy contract as they have brought out at Clause 1.4.2.1. "The ToR/Scope of work mentioned above are indicative and non-restrictive in nature. Other relevant services related to the corporatisation process, not expressly captured in the aforesaid scope of work, which upon being brought to the notice of the Consultant by the DDP, will also form an integral and mandatory part of the ToR [1]. Similarly, the Terms of Reference is EGoM allows discussing any other related matter. Multiple reviews at two different levels with open-ended options will make it possible to ensure a better outcome. In Management paradigm, it is not Plan A, 
which becomes the winner with poor execution skills, but it can be Plan B with better execution skills.

The Policy of MOD (Defence Production Policy: 2011, Draft Defence Production \& Export Promotion Policy (DPEPP) 2020), the EOI Cum RFP document by MOD for Consultant, Terms of Reference for Corporatisation of SPMCIL, the Cabinet Note for the formation of BSNL, the ToR of Kelkar Committee - Part II, Raman Puri Committee, Nair Committee have been examined. The endeavour should be while OFB metamorphoses to a new structure, it should get rid of the dragging elements that limit its potential and adopt new mechanism, the best practices from the corporate sector, be it PSU or Private or Autonomous Organisation so that it builds sustainable competitive advantage through the reforms.

The transformation strategy is proposed under the following levers; Strategic Transformation, EcoSystem Transformation, Learning from Past and Best of Class from Industry, Unit and Corporate Level Transformation, Structural Changes from Financial Perspective, Empowerment Mechanism, Talent Management and Employee Concerns and Change Management through better monitoring Consultant.

\subsection{Strategic Transformation}

The goal of the Transformation can be Emergence of OFB as a Solution Provider, System Integrator and Designer for ensuring Atma Nirbhara Bharat with Consortium of Industries for "Make in India" and "Design in India" to become part of the global defence value chains. Before selecting any model, there needs to be an examination of Pros and Cons of Alternate Models of Public-Private Partnership, Autonomous Corporations or any other suitable structure like holding Corporation under OFB or alongside OFB based on Global "State-Owned Corporations" (SOEs). The model so chosen should be compatible with the need to maintain War Time Reserve, ensure supply of Uneconomic order quantity, and deliver support for Life Time of Spares along with commercial functioning and sustainability.

Every country has to find its solution depending on its context, level of technological development and Capability. Whereas the USA relies on the Private sector, the French believe in the Public Sector. However, the real story starts here. While the US defence industry is mainly in private hands and the US Government emphasises market mechanisms, nearly four-fifths of the French defence industry is controlled by the State and broadly managed by the Government. Second, the French Parliament has much less power over defence decisions than does the US Congress. The commonality is that the Defence Industry in both countries runs with significant State patronage. Thus, support of the State will be necessary for any defence industry to become a global player.

The COVID 19 has thrown shattered the myth of the primacy of business efficiency. The pandemic has made us realise that resilience through safeguards and continuity are more important than efficiency. It also has made us appreciate that localised supply chain ensuring reliable supply with higher inventory level is better than cheaper sourcing options across the boundaries.
Government of India (GOI) has made the subject of reform as Corporatisation. Conversion to a Public Sector is not the only mechanism of Corporatisation. There can be various ways in which such autonomous functioning can happen. If an autonomous body or institution is a company, it is regulated by company law. If an autonomous body or institution is a society, it is governed by the law on the registration of societies. But in both cases, its board of directors can specify the rules of business for the body/institution. For simplicity sake, normally the boards of such bodies or institutions adopt the rules of the concerned Government or department under which they work, but only bypassing of a resolution to that effect. Despite the fact that the most common way, such autonomy is attained is through the formation of Public Sector Undertakings (PSU), there can be an alternate way of forming the same as $100 \%$ Government owned like Indian Space Research Organisation (ISRO), Defence Research and Development Organisation (DRDO), Council of Scientific \& Industrial Research (CSIR) etc. The Cabinet has the necessary mandate as per Rule 7 of the second schedule to form such Corporation. The best possible alternative need to be explored for achieving the lofted goal set by MOD.

\subsection{Eco System Transformations}

The new business environment is forcing organisations to rethink their strategies, organisational and business models, and their capabilities. In order to maintain their positions and grow, many companies are creating a community or becoming a part of a business ecosystem. The success of their efforts lies in alignment with such an ecosystem. The performance of the Industry radically improves, when the component of the ecosystem renews their relationship through agile and effective connection to the ecosystem.

The Business Ecosystem is adopting Digital Platforms, which are becoming powerful catalysts for superior performance, as has been evident in the emergence of some clusters across the world, like Silicon Valley. By leveraging powerful collaborative technology, Ecosystems more effectively address changes, achieving better outcomes on a global scale. More than the individual organisation, when the organisational ecosystems change in harmony, they reshape the value creation, providing superior value to its members and nation at large. The key to self-reliance and renewal of Military-industrial complex lies in the synergy of the players of the ecosystem. Thus, Transformation of OFB should go hand in hand with the reform of the ecosystem. The members in the ecosystem are the players of the value chain starting from Design Agency, Quality Assurance (QA) Agency, and Maintenance Agency coupled with the MOD as Policy Makers and Customer as the key element driving the change.

In light of the changes attempted, the force of the change will be far greater with closer Integration of OFB with R\&D to Academia, DRDO, CSIR, Private Sector R\&D, Global R\&D outside the boundaries of Units through Crowd-sourcing by a Special Purpose Vehicle (SPV)/PSU under OFB. There have been a sub-optimal performance of both OFB and DRDO, the first without appropriate technology finds difficult to penetrate 
the global market and DRDO without suitable production agency cannot bring out a product that is geared for ease of manufacturing known as 'Design for Manufacturing' philosophy. Hence, a suitable synergy between Design and Manufacturing agency is the need of the hour.

The UK Government in 1984 made Royal Ordnance an independent commercial organisation by corporatising Royal Ordnance Factories. The new name of the organisation was Royal Ordnance PLC, where part of the Royal Armament Research \& Development Establishment (RARDE) was transferred to Royal Ordnance PLC to provide an R\&D capability. International Military Sales (set up in 1967 to promote British made weapons and munitions overseas) was also merged with Royal Ordnance PLC [12]. Thus, the scope for the merger of DRDO laboratories with OFB needs to be explored, which can be advantageous to both OFB and DRDO. Transfer of DRDO Laboratories to the proposed entity/entities may help in unleashing new growth potential and Innovation in Ordnance Factories, as has been stated by the Government.

Empowerment and autonomy of OFB through the involvement of Quality Assurance (QA) agencies for Final Acceptance Inspection as per Global Practice of world-class manufacturing Organisation is another area of reform which can be contemplated. This will bring more efficiency for DGQA, for which the Government has already appointed a Consultant.

\subsection{Learning from Past and Best of Class from Industry}

Over several decades, MOD has instituted a mind-boggling number of panels, committees, working groups and task forces. It is better to take stock of the reports and examine the feasibility of undertaking reforms in light of their recommendations after examining the context and ramifications. There is a need to respect the wisdom of the past while distilling them for their compatibility in the new context. Past Committee Reports for the empowerment of OFB for an end to end full-fledged responsibility need to be examined for deeper reforms.

A Healthy Relationship between the Ministry and the Units under its working is normally established through a framework agreement, which is known as MOU in the Indian context. This helps in distancing between the Policy Makers and the executors through appropriate Governance Mechanism through the representation of Owner's Interest in the Board. A simultaneous hands-off approach from Ministry and freedom of Finance function to OFB need to be examined, whereas Accounts function can continue with Defence Accounting Department.

Examination of Best Practices of PSUs/ Indian Industry needs to be undertaken so that OFB can adopt suitable System, Structure and processes while avoiding undesirable Culture and Practices.

There had been a talk in MOD, whether it should transfer OFB and DPSUs (Defence PSUs) to other Ministries for avoiding conflict of interest. Considering the challenge of undertaking many national-level projects, which may require collaboration from CSIR, ISRO and private parties outside the
MOD, it may be explored if OFB has to put under PMO so that it can muster the national Capability through the significant citadel of Prime Minister's Office (PMO).

\subsection{Unit and Corporate Level Transformation}

Structural Transformation at Macro level is incomplete without appropriate change to Organisation Design at Micro Level. The talk of Corporate Structure must be accompanied by suitable changes in organisational design at the OFB Headquarter and Factory level.

It is important to distinguish between Organisational design and Organisational Structure. An organisational design is a process by which a manager selects and manages elements of Structure so that an organisation can control the activities necessary to achieve its goals. Organisational Structure is the formal system of task and activity relationship so as to be clear to how people coordinate their actions and use resources to achieve organisational goals. A good organisational design is important, as it can enhance the ability of the organisation to deal with contingencies. A good organisational design builds competitive advantage for better creation of value and influences an organisation's ability to be innovative and efficient. A good organisational structure and design help improve communication, increase productivity, and inspire Innovation. It creates an environment where people can work effectively.

In addition, it must be examined how to enhance medium and long term prospects for Sustainable Growth of each factory and Operational Excellence with a portfolio of products and competencies with the scope of collaborations with Indian Industry / Global Defence MNCs. The brass tracks of strategy implementation at unit level lie in building Capability for future products after analysing the technology gaps. Unit -wise Augmentation and Capacity addition must be crafted for better support to Spare Part, Overhauling for Life Time Support, support to Defence Corridors, "Start-Up India" Mission and MSMEs and "Skill India."

It needs to be scrutinised how Unit level Structural Transformations Strategy through Business Process reengineering and Digital Transformations/ Industry 4.0, can complement with the simplification of Plethora of Rules for faster decision making and better Supply Chain Management through collaborative contracts. A simple house with neat rules will be more amenable for the new order of the digital world.

OFB carries its own health care apparatus for tertiary health care in the industrial setting. It needs to be examined, how the same system can best serve Ayushman Bharat (Healthy Mission of Government of India) and OFB at the same time.

\subsection{Structural Changes from Financial Perspectives}

It may be possible to make OF Units as growth engines that can boost manufacturing, augment exports and generate employment through appropriate measures of incentivisation through Tax incentives since as a Public Sector Unit. OFB in its new incarnation should contribute to implementing many 
of the schemes of GOI for Skill India, Backward Area Development in some of the remote part of India. The ultimate test is the growth of the entire Military-Industrial Complex as a whole, contributing to the National Economy.

It may be examined, whether OFB Units can be granted status as that in Export Processing Zones (EPZs) and Export Oriented Units (EOU) or an infrastructure industry status to make OFB Competitive. It may be explored whether some element of cost due to social welfare measure can be taken care through Taxation exemption, which puts OFB at a disadvantage versus the private sector players. The contribution for equity consideration, if compensated through various incentives, can make OFB more efficient for a competitive business.

\subsection{Change Management Through Better Monitoring Consultant}

The horizon for change contemplated for OFB should ensure that they remain competitive and successful. However, looking at the past, there have been many examples in legacy organisations, where changes that were poorly managed, did not deliver results and created stress and confusion in the organisation. Under-delivering on change cannot be acceptable and tolerable in moving forward. Past research has brought out that transforming organisations is a herculean task The success stories depend on, how the leaders communicate the vision and walk the talk in order to make change efforts succeed. The past studies throw light on the importance of changing organisational culture and employees' attitudes. They bring out a harmony between the top-down transformation efforts and participatory approaches for change. They bring out that change management succeeds when the change-makers win people's hearts and minds.

Addressing the people side of change is the expectation rather than the exception in the organisation. This can be possible when Change Management is undertaken as a process, which can minimise possible negative outcomes and increase positive results. The quality of the change management strategy is directly linked to the appropriate diagnosis done by the Consultant. Hence, the Consultant may be engaged for Ground Level 'Zero' Transformation by rigorous diagnosis with payment linked to Outcome and Performance guarantee linked to the outcome over ten years' time. Commensurate accountability for Policy Makers any other suitable change management framework needs to be adopted for making the change work.

It is worth a question, whether Big Bang Reform should be attempted at one go, or scaling up should be done after a pilot. It needs to be examined whether any interim preparatory period should be entertained, making the ground ready for reform or steer it as and when the reforms are undertaken.

With a risk management plan, OFB can better prepare for the unexpected, minimising risks and extra costs before they happen. By considering potential risks or events before they happen and having a risk management plan in place, MOD can ensure that the public money is saved and the organisation's future is protected against unwarranted happening.
The ability and efforts undertaken at this stage to identify risks and manage them before they even affect the business can go a long way in ensuring the success of Transformation. The ability to manage risk will make OFB act more confidently on future business decisions despite any obstacles they may face in the way, knowing that they have anticipated the same and they have put a suitable mechanism to address the same.

\subsection{Talent Management and Employee Concerns}

Talent Management is "a set of integrated organisational HR processes designed to attract, develop, motivate, and retain productive, engaged employees. It is of utmost importance that HR should lead the change management not only by initiating and leading the change but also by serving as a facilitator for changes. The HR department needs to play a greater role for communication, implementation and tracking of major changes. HR can provide strategic support to the change management by calculating key performance indicators (KPIs), measuring, tracking and communicating these results. By championing change, HR can help the organisation increased buy-in, comfort and support for change across departments, thereby increasing the success of change initiatives.

Frederickson and Smith consider that the state "is now less bureaucratic, less hierarchical, and less reliant on a central authority to mandate action" [13]. Accountability needs to be ensured through higher performance rather than discharging a specific policy goal within the confines of the law. Hence suitable performance management mechanism needs to be in place from top to bottom.

The Structure of various components of manpower such as Managers, Supervisors and Workers for Future Growth of the Industry should be examined in line with best practices in Industry. Delivering more with less can be done through optimal outsourcing and other models of Partnership for Staffing and Management. Supplementing manpower with ROBOTs, COBOTs, and BOTs will help OFB to remain lean.

The voice of the customer can be better integrated to the culture of OFB by tapping customer expertise of Service Officers and Technical Staff at various levels through Tenure based Contracts, with jeopardising career prospect of existing employees.

The change for future can be driven through by Capacity Building of employees for making them Ready for Future by Redeployment, Retraining and Severance Plan in line with "Mission Karmayogi" (HR Mission of Government of India for Skilled Employee) [14]. Any new Capacity Building must address the needs of developing new Capability, particularly for Industry 4.0, R\&D, and Finance and Marketing, key success factor for the new world.

The sustainability of change and the depth of change can be ensured through Real-time Dash Board Performance Management System from Top to bottom and suitable incentive system across the board to drive Innovation and productivity.

Change becomes a success when stakeholder is the part 
that new Win-Win partnership. Engagement and involvement of the Federations/ Trade Unions/ Associations will be required for harmonious relationship for building while ensuring the protection of Service conditions like Pay, Promotion, Perquisites including Health Facilities, CSD (Canteen Stores Department) and pension including benefits of Cadre restructuring and promotion at par with Central Services and genuine expectations of employees at the time of joining.

\subsection{Empowerment Mechanism}

The organisational autonomy is related to the internal decentralisation of managerial decision-making in the context of Public Sector. The decentralisation of managerial authority has the potential to more committed and empowered middle and lower managers resulting in better organisational performance [15].

Policies change over time and support promised by the MOD need to be given the mandate from the Acts, Rules and Procedures. The formation of Autonomous Corporation can be effected through an Act of Parliament. It is necessary to assure the support through suitable changes in the Defence Acquisition Policy and Defence Procurement Manual for optimum Capacity Utilisation of the national infrastructure for sustainability and growth. This will go a long way in allaying fears in the mind of employees on the adverse impact of the business cycle or any unfavourable development of the regulatory framework. When OFB is empowered, MOD will have fewer worries, and more accountability can be demanded from the new entity.

\section{Conclusion}

A transformation, planed for OFB will bring a major shift in an organisation's capabilities for higher performance for an Atma Nirbhara Bharat. The real test in the outcome impact will be measured by unleashing the power of Innovation, boosting exports exponentially, improving the quality radically, creating profitable and self-sustaining arms production system in the country, agility in absorbing ToT, besides forming Joint Venture (JVs) with other countries including the acquisition of foreign companies.

The change need not revolve around a single pivot of Corporatisation, but a lot many changes around the same, to the changes in Strategy, Organisation Design, EcoSystem Transformation, Culture and empowerment so that OFB has the agility to undertake the change with the times and become dynamically competitive. The EGoM leadership must orchestrate the cultural shift by actively engaging the stakeholder and framing a debate by articulating desirable future and keeping cards open for the options for achieving that future. The EGoM leadership must save the best of OFB's past, and change the rest in a most befitting way so that OFB reinvents itself. Openness to the agenda, broadening the canvass of change, providing support for the change and monitoring the change will be the key to the success of the strategic
Transformation of OFB When somebody examines the post-script, India should be proud of undertaking the right reforms with the right methodology that yielded the right results by the leadership of EGoM and accountability of the Consultant and Policy Makers in MOD.

\section{Note}

Aatma Nirbhar Bharat Abhiyan: The Prime Minister has announced an INR 200000 billion economic package under the 'Aatma Nirbhar Bharat Abhiyaan', to aid India out of the Coronavirus crisis by making it self-reliant.

One Crore means 10 Million.

\section{References}

[1] MOD, 2020. Expression of Interest cum Request for Proposal for Selection of Consultant for Providing strategic and implementation management consulting services to assist the Ministry of Defence in the process of Corporatisation of the Ordnance Factory Board. s. 1.: MOD, MOD No. 18 (4)/2014/Restructuring of OFB/Director (P\&C)/DDP.

[2] PIB, 2020. MoD appoints KPMG Advisory Services led consortium for consultancy on Corporatisation of OFB. [Online] Available at: https://pib.gov.in/PressReleaseIframePage.aspx?PRID=16530 66 [Accessed 1010 2020].

[3] Anderson, J. E., 1994. Public policymaking. 2nd ed. ed. Princeton, NJ: Houghton Mifflin.

[4] Howlett, M. \& Ramesh, M., 1995. Studying public policy: Policy cycles and policy subsystems. Toronto: Oxford University Press.

[5] Majone, G., 1989. Evidence, argument and persuasion in the policy process. New Haven: Yale University Press.

[6] Young, E. \& Quinn, L., 2002. Writing Effective Policy Papers: A guide for policy advisers in Central and Eastern Europe. s. 1.: Open Society Institute.

[7] PIB Delhi, 2020. Corporatisation of Ordnance Factory Board: Government constitutes Empowered Group of Ministers headed by Raksha Mantri. [Online] Available at: https://pib.gov.in/PressReleaseIframePage.aspx?PRID=16533 74 [Accessed 30 October 2020].

[8] Hammer, M. \&. C. J., 1993. Reengineering the Corporation: a manifesto for business revolution. New York: HarperBusiness.

[9] Gleeson, B., 2017. 1 Reason Why Most Change Management Efforts Fail. [Online] Available at: https://www.forbes.com/sites/brentgleeson/2017/07/25/1-reas on-why-most-change-management-efforts-fail/\#2dd96c9c546 b [Accessed 0909 2020].

[10] IBM Institute for Business Value, 2014. Making change work ... while the work keeps changing. s. 1.: IBM.

[11] BCG, 2020. Beating the Change Management Odds. [Online] Available at: https://www.bcg.com/capabilities/change-management/default [Accessed 0909 2020]. 
[12] Wiki, 2020. Royal Ordnance. [Online] Available at: https://en.wikipedia.org/wiki/Royal_Ordnance [Accessed 10 $102020]$.

[13] Frederickson, H. George, and Kevin B. Smith, 2003. The Public Administration Theory Primer, Boulder, CO: Westview Press.

[14] PIB Delhi, 2020. Cabinet approves "Mission Karmayogi"National Programme for Civil Services Capacity Building
(NPCSCB). [Online] Available at: https://pib.gov.in/PressReleseDetailm.aspx?PRID=1650633 [Accessed 30 October 2020].

[15] Wynen, J., Verhoest, K., and Rubecksen, K., 2014. Decentralisation in Public Sector Organizations, Do Organizational Autonomy and Result Control Lead to Decentralization Toward Lower Hierarchical Levels? Public Performance \& Management Review, 37 (3). 496-520. 